\title{
Convalescent plasma therapy in patients with COVID-19
}

\author{
Luz del C. Tarín-Arzaga, María del R. Salazar-Rojas, Dalila M. Alvarado Navarro, David Gómez-Almaguer*, \\ and Carlos S. Rodríguez-Roque
}

Hematology Service, School of Medicine and "Dr. José Eleuterio González" University Hospital, Universidad Autónoma de Nuevo León, Monterrey, Nuevo Leon, Mexico

\begin{abstract}
The COVID-19 pandemic is caused by severe acute respiratory syndrome coronavirus 2, a new and different coronavirus. Since almost every continent in the world has been affected, the global actions have been focused on prevention, detection, and patient monitoring with no specific treatment until now. Classical and historical interventions have remerged as options including convalescent plasma. The use of convalescent plasma has become more important during large-scale epidemics, such as Mid-East respiratory syndrome-CoV and influenza pneumonia, data regarding support its clinical use. Unfortunately, published clinical data on the usefulness of convalescent plasma in patients with COVID-19 are scarce, but it has shown good clinical outcomes. There are no reports of adverse events in clinical trials of patients receiving convalescent plasma treatment for COVID-19. Nevertheless, FDA has issued its recommendations for the use of convalescent plasma as an option that may provide clinical effect for treatment during the public health emergency caused by COVID-19, with recommendations to avoid adverse effects in centers developing clinical trials with coronavirus convalescent plasma.
\end{abstract}

Key words: COVID-19. Severe acute respiratory syndrome coronavirus 2. Convalescent plasma.

The world is now facing another new virus pandemic. There is a global outbreak of a new and different coronavirus. COVID-19 is a disease caused by severe acute respiratory syndrome coronavirus 2 (SARS-CoV-2). This viral agent belongs to the family Coroviridae and subfamily Orthocoronavirinae. It is a single-stranded positive-sense RNA virus, with the structure of a group $\beta$-coronavirus, including Mid-East respiratory syndrome-CoV and SARS-CoV ${ }^{1}$. Almost every continent in the world has been affected. The infection has been diagnosed in all groups of ages, but it is uncommon in children and adolescents. At present, there is no ideal treatment or specific anti-COVID-19 drug. Therefore, the World Health Organization has focused on infection prevention, detection, and patient monitoring ${ }^{2}$. At present, treatment options include antiviral, antimalarial, steroid treatments, and among others. However, the efficacy of these drugs is still unknown ${ }^{3}$. In this setting, the alternative of using therapeutic plasma collected from patients that have already recovered from COVID-19 is appealing. The administration of plasma as a treatment for infectious diseases is not new, and it has been used over many years for several infectious agents, including a variety of different virus. Convalescent plasma therapy (CPT), also known as passive immunization, consists of intravenous administration of plasma obtained from a patient who has just recovered from an infection and, in which it is possible to find IgM

\section{Correspondence:}

*David Gómez-Almaguer

E-mail: dgomezalmaguer@gmail.com
Available online: $18-06-2020$

Date of reception: 04-05-2020

Date of acceptance: 07-05-2020

DOI: 10.24875/RMU.M20000044
Medicina Universitaria. 2020;22(2):88-90 www.medicinauniversitaria.org

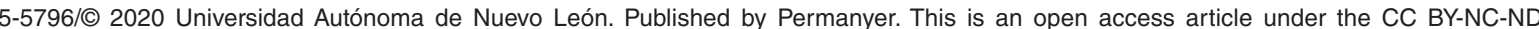
license (http://creativecommons.org/licenses/by-nc-nd/4.0/). 
Table 1. Donor eligibility

1. Informed consent

2. Donor without a history of blood transfusion and female donors who have never been pregnant

3. Prior diagnosis of COVID-19 documented by laboratory test or clear case history symptoms when test was no available

4. At least 14 days should have passed since full recovery or at least 14 days after laboratory evidence for viral RNA clearance from the upper respiratory tract

5. Asymptomatic COVID-19 laboratory-confirmed persons may also donate convalescent plasma at least 14 days after testing positive

and IgG antibodies against a certain microorganism, in this case against SARS-CoV-2, with the aim of neutralizing the virus and reducing the systemic inflammatory response ${ }^{4}$. In contrast, active immunization or vaccination requires the induction of an immune response that takes time to develop and varies depending on the vaccine recipient. Thus, passive antibody administration provide immediate immunity to susceptible individuals. Depending on the antibody amount, the protection conferred by the transferred antibodies can last weeks or months. Apheresis is the recommended procedure to obtain plasma. This procedure is based on a continuous centrifugation of blood from donor to allow a selective collection of $400-800 \mathrm{~mL}$ of plasma in a single procedure that can be fractionated and frozen. During apheresis, in addition to neutralizing antibodies, other proteins such as anti-inflammatory cytokines, clotting factors, and other proteins are obtained from donors.

The use of convalescent plasma has become more important during large-scale epidemics. The experience obtained in epidemics such as SARS and influenza pneumonia support its clinical utility. Patients who received this treatment had a shorter hospital stay and lower mortality, and no immediate adverse effect noted after plasma infusion ${ }^{5,6}$. A meta-analysis involving 1703 influenza pneumonia patients who received convalescent plasma showed reduced viral load and decreased in mortality by $21 \%{ }^{7}$. It is important to note that the FDA has issued its recommendations for the use of convalescent plasma as an option that may provide clinical effect for treatment during the public health emergency caused by COVID-198.

Published clinical data on the usefulness of convalescent plasma in patients with COVID-19 are scarce. A systematic review included five studies with a total of 27 patients, most of them male, residents of China, between 28 and 75 years old. Only 21 patients were in the intensive care unit, 14 of them received mechanical ventilation. The plasma dose used was 80 $2400 \mathrm{ml}$; in 1-8 fractions, no serious adverse events were observed. All patients also received some kind of antiviral treatment. Although all studies reported until now were considered to have the risk of bias due to the heterogeneity of patients and centers, many were case reports and case series; it is relevant to highlight that all the studies described a good clinical result including a significant reduction in viral load and an increase in neutralizing antibodies after the $\mathrm{CPT}^{9}$. Possible mechanism of actions of CPT has been suggested, including antiviral properties and immunomodulation through receptors Fab and Fcy stimulation, and also, it is proposed that plasma has the capability of enhance the anti-inflammatory effect of dendritic cells regulation ${ }^{10}$.

At present, our center is developing a randomized, double-blind, and Phase II controlled clinical trial evaluating the efficacy and safety of convalescent plasma from SARS-CoV-2. It is important to consider that the evaluation of the donor is in the same way as all blood donors and must be carried out in accordance with local current legislation. Before the collection, the screening studies are as follows: complete blood count, blood group determination, and serological tests for rose Bengal, Trypanosoma cruzi, hepatitis C virus, hepatitis B, HIV, Treponema pallidum, and cytomegalovirus. In addition, the donor must be asymptomatic 10-14 days with a negative polymerase chain reaction test to SARS-CoV-2 ${ }^{11,12}$ (Table 1).

We performed plasma recollection by apheresis since a leukoreduced product and greater volumes could be obtained in a single session, opening the door for more frequent donations ${ }^{13}$. The maximum amount of volume to extract is $600 \mathrm{~mL}$; however, a greater volume of plasma from the donor could be obtained; as long as, volume replacement is administered ${ }^{5}$.

Until now, there are no reports of important adverse events in patients receiving convalescent plasma treatment ${ }^{14}$. There is a hypothesis that there could be an inflammatory response in addition to the inherent risks for plasma transfusion: transmission of infectious agents, circulatory overload, acute lung injury, lowgrade fever, allergic reaction, etc. Some of the FDA's recommendations are the determination of anti-HLA antibodies (in donors with a history of immunization) and the inactivation of pathogens, leading to increased transfusion safety ${ }^{15}$. However, the cost is a limitation in low-middle income countries. Randomized clinical trials are needed to define the efficacy of this therapy; 
however, with the information obtained so far, convalescent plasma could be a useful therapeutic option with promising evidence on safety and effectivity.

\section{Conflicts of interest}

The author declares that they have no conflicts of interest.

\section{References}

1. Zhang L, Liu Y. Potential interventions for novel coronavirus in China : a systematic review. J Med Virol. 2020;92:479-90.

2. Wu Z, McGoogan JM. Characteristics of and important lessons from the coronavirus disease 2019 (COVID-19) outbreak in china summary of a report of 72314 cases from the Chinese center for disease control and prevention. JAMA. 2020;323:1239-42

3. Lu H. Drug treatment options for the 2019-new coronavirus (2019-nCoV) Biosci Trends. 2020;14:69-71.

4. Soo YO, Cheng Y, Wong R, Hui DS, Lee CK, Tsang KK, et al. Retrospective comparison of convalescent plasma with continuing high-dose methylprednisolone treatment in SARS patients. Clin Microbiol Infect. 2004; 10:676-8.

5. Brown BL, McCullough J. Treatment for emerging viruses: convalescent plasma and COVID-19. Transfus Apher Sci. 2020;2020:102790.
6. Liu W, Fontanet A, Zhang PH, Zhan L, Xin ZT, Baril L, et al. Two-year prospective study of the humoral immune response of patients with severe acute respiratory syndrome. J Infect Dis. 2006;193:792-5.

7. Luke TC, Kilbane EM, Jackson JL, Hoffman SL. Meta-analysis: convalescent blood products for Spanish influenza pneumonia: a future H5N1 treatment? Ann Intern Med. 2006;145:599-609.

8. Food and Drug Administration. Recommendations for Investigational COVID-19 Convalescent Plasma, Content Current. Available from: https:// www.fda.gov/vaccines-blood-biologics/investigational-new-drug-ind-or-device-exemption-ide-process-cber/recommendations-investigational-covid-19-convalescent-plasma. [Last accessed on 2020 Apr 13].

9. Rajendran K, Narayanasamy K, Rangarajan J, Rathinam J, Natarajan M, Ramachandran A. Convalescent plasma transfusion for the treatment of COVID-19: systematic review. J Med Virol. 2020. doi:10.1002/jmv.25961. doi:10.1002/jmv.25961

10. Rojas M, Rodriguez Y, Monsalve DM, Acosta-Ampudia Y, Camacho B, Gallo JE, et al. Convalescent plasma in Covid-19: possible mechanisms of action. Autoimmun Rev. 2020;2020:102554.

11. NORMA Oficial Mexicana NOM-253-SSA1-2012, Para la Disposición de Sangre Humana y Sus Componentes con Fines Terapéuticos. $3^{\text {rd }}$ ed. Norma Oficial Mexicana (Normatividad Mexicana); 2012.

12. Actualización del Lineamiento Técnico Para la Selección y Diferimiento de Donantes en México, en Relación al Coronavirus 2019-COVID-19 y Otras Infecciones Respiratorias Agudas. Versión 04. Centro Nacional de la Transfusión Sanguínea. Dirección General; 2020.

13. Liumbruno GM, Grazzini G. Convalescent plasma: new evidence for an old therapeutic tool? Blood Transfus. 2016;14:152-7.

14. Roback JD, Guarner J. Convalescent plasma to treat COVID-19 possibilities and challenges. JAMA. 2020;323(16):1561-2 doi:10.1001/jama 2020.4940

15. Brunk D. FDA OKs Emergency use of Convalescent Plasma for Seriously III COVID-19 Patients. Medscape; 2020. p. 28-9. 